\title{
Anabases
}

ANABASES Traditions et réceptions de l'Antiquité

$24 \mid 2016$

Varia

\section{Agnès Bérenger et Olivier Dard (dir.), Gouverner par les lettres, de l'Antiquité à l'époque contemporaine}

\section{Alexandre Massé}

\section{(2) OpenEdition}

\section{Journals}

Édition électronique

URL : http://journals.openedition.org/anabases/5739

DOI : 10.4000/anabases.5739

ISSN : 2256-9421

Éditeur

E.R.A.S.M.E.

\section{Édition imprimée}

Date de publication : 10 novembre 2016

Pagination : 332-334

ISSN : 1774-4296

\section{Référence électronique}

Alexandre Massé, «Agnès Bérenger et Olivier Dard (dir.), Gouverner par les lettres, de l'Antiquité à

l'époque contemporaine », Anabases [En ligne], 24 | 2016, mis en ligne le 15 novembre 2016, consulté le 23 septembre 2020. URL : http://journals.openedition.org/anabases/5739 ; DOI : https://doi.org/ 10.4000/anabases.5739

Ce document a été généré automatiquement le 23 septembre 2020

(c) Anabases 


\title{
Agnès Bérenger et Olivier Dard (dir.), Gouverner par les lettres, de l'Antiquité à l'époque contemporaine
}

\author{
Alexandre Massé
}

\section{RÉFÉRENCE}

Agnès Bérenger et Olivier Dard (dir.), Gouverner par les lettres, de l'Antiquité à l'époque contemporaine, Metz, Centre de Recherche Universitaire Lorrain d'Histoire, 2015, 443 p. 25 euros / isbn 2-85730-061-1

1 Dans cet ouvrage, Agnès Bérenger, professeur d'histoire romaine à l'Université PaulValéry Montpellier 3, et Olivier Dard, professeur d'histoire contemporaine à l'Université Paris-Sorbonne, présentent les actes du colloque qui s'est tenu à Metz les 10-12 octobre 2013. Dans une brève introduction, ils exposent les choix qui structurent leur démarche scientifique. Le colloque portait sur l'usage des lettres comme vecteurs de pouvoir. Sont donc appréhendés tous les courriers susceptibles d'avoir exercé une influence politique, ce qui inclut les correspondances publiques, diplomatiques et administratives, mais aussi les lettres de recommandation et certains échanges épistolaires privés. Les organisateurs ont donc fait le choix d'ouvrir, autant que possible, l'angle d'approche en abordant les lettres comme des vecteurs de la pensée, de l'action politique, d'informations, de conseils, d'ordres, de débats, etc. Cette approche soulève tout particulièrement la question des divergences entre le discours et les pratiques concrètes, mais aussi le problème de l'efficacité des correspondances dans une perspective rejoignant la problématique de l'opposition centre/ périphéries.

Dans l'objectif d'un élargissement maximal, les organisateurs ont également fait le choix du temps long pour s'efforcer, avec succès, de dépasser les questionnements propres à chaque période. Il s'agit, pour eux, de prouver l'existence d'invariants politiques, comme l'apparition de bureaucraties et de technicités dans les États 
organisés. Il a donc été demandé aux contributeurs de réfléchir à partir de méthodes comparables, notamment en travaillant à une typologie des correspondances qu'ils utilisent, à leur fréquence et leur durée, aux réseaux embrassés par elles et à leurs implantations territoriales afin de les cartographier. En fin de compte, cet ouvrage regroupe vingt-et-une présentations réparties autour de cinq thèmes: "Informer, renseigner ", "Conseiller, négocier ", "Art et pratique du gouvernement : bien et mal gouverner », "Recommander, nommer» et "Expressions du pouvoir». Suivant la logique présentée par les auteurs, chacune des cinq parties de l'ouvrage contient des contributions portant sur plusieurs périodes historiques, l'époque contemporaine étant moins présente.

3 La partie «Informer, renseigner » contient cinq interventions. Julien Briand y étudie la correspondance entre le roi et la ville de Reims au XVe siècle (p. 13-37) et Klara Hübner s'y intéresse à la messagerie de Fribourg également au XVe siècle (p. 39-52). François Brizay présente une étude des correspondances des consuls et diplomates en poste à Rome et dans le Royaume de Naples au début du XVIIie siècle en insistant sur leur mission informative (p. 53-72). Ferenc Tóth analyse l'influence de la correspondance diplomatique de Louis XIV durant la guerre d'indépendance hongroise (17031711) (p. 73-94). Julie d'Andurain s'intéresse à la correspondance privée des officiers coloniaux, notamment à celle de Lyautey (p. 95-113).

4 La partie "Conseiller, négocier» s'organise également autour de cinq interventions. Armand Jamme étudie la correspondance entre le Pape et les souverains au milieu du xive siècle (p. 117-145). François Pernot analyse la pratique des consulta - un avis écrit par un conseiller à propos d'une lettre ou d'une demande reçue par le roi - dans l'Espagne de Philippe II (p. 147-155). Thierry Rentet s'intéresse à la correspondance de M. de Gordes, lieutenant général du roi, au moment où il gouverne le Dauphiné (1564-1566) (p. 157-175). Claire Buchet se penche sur la correspondance propédeutique entre une mère, Charlotte-Marguerite de Montmorency, et un fils, Louis II de Bourbon, le futur Grand Condé, de 1643 à 1646 (p. 177-187). Jean-François Plamondon analyse l'importance du réseau épistolaire de Marie de l'Incarnation dans la fondation du monastère des Ursulines à Québec dans les années 1630 (p. 89-206).

5 La partie « Art et pratique du gouvernement : bien et mal gouverner " s'organise aussi autour de cinq interventions. Rémy Poignault étudie la correspondance du rhéteur Fronton et ses conseils sur l'art de gouverner au II siècle (p. 209-232). Fanny Firon s'intéresse aux lettres adressées par la population aux administrateurs d'oxyrhynchos dans la province romaine d'Égypte du $\mathrm{i}^{\mathrm{er}}$ siècle au iv ${ }^{\mathrm{e}}$ siècle (p. 233249). François-Xavier Romanacce analyse la correspondance de l'évêque de Carthage, Cyprien, pendant la persécution anti-chrétienne de 250-251 (p. 252-269). Christiane Veyrard-Cosme se penche sur les lettres de Charlemagne (p. 271-285). Amandine Le Roux étudie la pratique épistolaire comme moyen de gouvernance financière à travers l'exemple des échanges entre la papauté et ses collecteurs aux xiv ${ }^{\mathrm{e}}$ et $\mathrm{XV}^{\mathrm{e}}$ siècles (p. 287-310).

6 La partie « Recommander, nommer » contient quatre interventions. Christian Settipani analyse les parentés implicites ou explicites dans les recueils épistolaires gallo-romains (p. 313-346). Luciana Furbetta s'intéresse aux lettres de recommandation en Gaule du v $\mathrm{v}^{\mathrm{e}}$ siècle au vIIie siècle (p. 347368). Jonathan Barbier se penche sur la pratique des recommandations médicales chez Français-Vincent Raspail de 1840 à 1862 et ses liens avec la politique (p. 369-388). Julie Bour étudie les interactions entre la pratique de la faveur et la corruption à travers les lettres de recommandation en Meuse de 1880 à 
1980 (p. 389-403). Enfin, la partie « Expressions du pouvoir », la plus courte, se limite à deux interventions. Agnès Bérenger y étudie la pratique épistolaire des gouverneurs de province dans l'Empire romain en se focalisant sur les lettres adressées aux administrés ou à d'autres représentants du pouvoir central (p. 407-423). François Bérenger se penche sur l'utilisation de la correspondance par le roi Charles II d'Anjou pour gouverner la Sicile (1289-1294) (p. 423-440).

\section{AUTEURS}

\section{ALEXANDRE MASSÉ}

Université Toulouse-Jean Jaurès (UT2J)

masse.alexandre.pierre@gmail.com 